\title{
Formação continuada numa perspectiva da educação para a inteireza: \\ uma necessidade do professor de creche
}

\author{
MEINICKE, Dinorá ${ }^{1}$ \\ SANTOS, Andréia Mendes dos²
}

\section{RESUMO}

O presente texto compartilha implicações que emergiram de uma pesquisa qualitativa de abordagem hermenêutica, cujo propósito foi compreender como as Ações de Formação Continuada - FC ofertadas ao Professor de Creche, pela Secretaria Municipal de Educação - SME de Florianópolis/SC, no período 2013-2015, instigavam uma formação na perspectiva de uma Educação para a Inteireza. Os achados desse estudo desvelaram que: as concepções de FC que sustentaram as ações ofertadas pela SME foram sendo aprimoradas ao longo do período; ao serem pensadas, as ações de FC, não contemplavam as dimensões constitutivas do SER no seu planejamento, contudo, embora a Secretaria não tenha concebido tais ações com esse propósito, entende que essas dimensões permearam o seu desenvolvimento e reconhece a importância de viabilizar a FC nesta perspectiva, porém, assinala fragilidade acerca do entendimento do assunto, aponta necessidade e interesse de investir em estudos que possibilitem aprimorar a compreensão da FC na perspectiva da Educação para a Inteireza.

Professores de Creche. Formação Continuada. Educação para Inteireza.

\section{Continuing education from the perspective of Education for Integrality: a need of the Kindergarten Teacher}

\section{ABSTRACT}

This paper shares implications that emerged from a qualitative research with a hermeneutic approach, whose purpose was to understand how the Actions of Continuing Education - CE offered to the Kindergarten Teacher, by the Municipal Secretary of Education - SME of Florianópolis / SC, in the period

\footnotetext{
${ }^{1}$ Doutora em Educação pela Pontifícia Universidade Católica do Rio Grande do Sul. Professora Educação Infantil - Rede Municipal de Ensino de Florianópolis/SC. E-mail: dinora.meinicke@prof.pmf.sc.gov.br; dinora.meinicke@acad.pucrs.br. Lattes: http://lattes.cnpq.br/4922137755945957. ORCID: https://orcid.org/0000-0003-4541-6168

2 Doutora em Serviço Social na PUCRS. Professora Escola de Humanidade PUCRS Professora/ Pesquisadora PPGEDU. E-mail: andreia.mendes@pucrs.br; andreia.mendes@pq.cnpq.br. Lattes: http://lattes.cnpq.br/9544763044134842. ORCID:
} https://orcid.org/0000-0001-7013-0239.

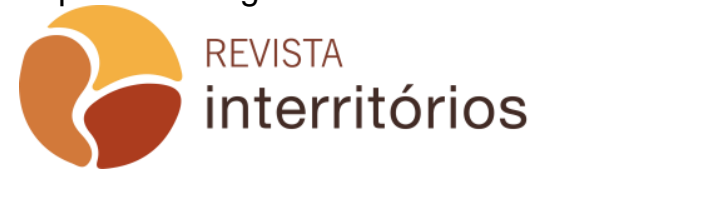

Interritórios | Revista de Educação Universidade Federal de Pernambuco, Caruaru, BRASIL | V.5 N.9 [2019] 
2013-2015, instigated training in the perspective of an Education for Integrality. The findings of this study revealed that: the CE conceptions that supported the actions offered by the SME were being improved over the period; When thinking about CE actions did not contemplate the constitutive dimensions of SER in its planning, however, although the Secretariat did not conceive such actions for this purpose, it understands that these dimensions permeated its development and recognizes the importance of enabling CE in this perspective. However, it points out fragility about the understanding of the subject, points out the need and interest to invest in studies that enable the understanding of CE to be improved from the perspective of Education for Integrality.

Kindergarten Teachers. Continuing Education. Education for Integrality.

\section{Formazione continua dal punto di vista dell'educazione alla integrità: una necessità per gli insegnanti di asilo}

\section{RIASSUNTO}

Il presente testo condivide le implicazioni emerse da una ricerca qualitativa sull'approccio ermeneutico, il cui scopo era comprendere come le azioni di formazione continua offerte all'insegnante di scuola materna, dal Segretariato per l'educazione municipale de la cittá di Florianópolis / Sud del Brasil, nel 2013-2015, ha istigato una formazione nella prospettiva di un'educazione per il tutto. I risultati di questo studio hanno rivelato che: le concezioni della formazione continua. Le azioni offerte dalle secreterie de insegno sono state migliorate nel corso del periodo pero non hanno contemplato le dimensioni costitutive del ESSERE nella sua pianificazione. Sebbene il Segretariato non abbia concepito tali azioni a tale scopo, queste dimensioni permeano il suo sviluppo e riconosce l'importanza di abilitare con una fornazione continua. In questa prospettiva, tuttavia, sottolinea la fragilità della comprensione della materia, la necessità e l'interesse a investire in studi che consentano di migliorare la comprensione di questa formazione dal punto di vista dell'Educazione per essere completo.

Insegnanti di scuola materna. Formazione permanente. Educazione per la completezza.

\section{La educación continua desde la perspectiva de la Educación para la Integralidad: una necesidad del maestro de jardín de infantes}

\section{RESUMEN}

Este artículo comparte las implicaciones que surgieron de una investigación cualitativa con un enfoque hermenéutico, cuyo propósito era comprender cómo las Acciones de Educación Continua - CE ofrecieron al Maestro de Kindergarten, por la Secretaría Municipal de Educación - SME de Florianópolis / SC, en el período 2013-2015, instigó la capacitación en la perspectiva de una

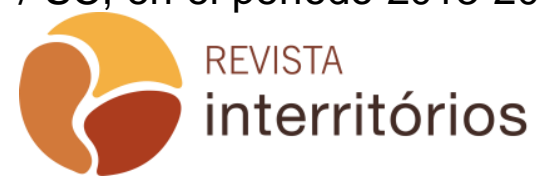


Educación para la Integralidad. Los resultados de este estudio revelaron que: las concepciones de CE que respaldaron las acciones ofrecidas por las PYME se mejoraron durante el período; Sin embargo, al pensar en las acciones de CE no contempló las dimensiones constitutivas de SER en su planificación, aunque la Secretaría no concibió tales acciones para este propósito, entiende que estas dimensiones impregnaron su desarrollo y reconoce la importancia de habilitar CE en esta perspectiva. Sin embargo, señala la fragilidad sobre la comprensión del tema, señala la necesidad y el interés de invertir en estudios que permitan mejorar la comprensión de la CE desde la perspectiva de la Educación para la Integralidad.

Maestros de Kindergarten. Educación continua. Educación para la integralidad.

\section{INTRODUÇÃO}

Se o Ser humano "é a única criatura que precisa ser educada" para [...] "tornar-se o que pode ser" e "para tal, [...] deve educar-se, 'tornar-se por si mesmo"', como afirma Charlot (2000, p. 51-52), a Formação Continuada é um desafio a ser assumido ao longo da vida; se o Ser humano não se constitui apenas de razão, mas também de alma e coração, como sustenta Catanante (2000), justifica-se a crença de que toda Formação Continuada pressupõe e requer ações que possibilitem uma formação na perspectiva de sua Inteireza, pois, o "Professor é a Pessoa e a Pessoa é o Professor" (NÓVOA, 2009, p. 38); e, se a Secretaria Municipal de Educação de Florianópolis/SC elege "a Educação Integral como concepção fundante do currículo" (FLORIANÓPOLIS, 2015a, p. 38) para a Educação Básica, o Professor de Creche $^{3}$ necessita ser assim considerado em sua existencialidade e em sua formação, o que entendemos, torna essencial o investimento em Ações de Formação Continuada que oportunizem essa formação na perspectiva de uma Educação para a Inteireza, uma vez que, se a esse profissional cabe à responsabilidade e o compromisso de trabalhar com um sujeito integral, ofertando uma educação integral, a sua Formação Continuada necessita estar fundamentada e "comprometida com a formação humana, na sua integralidade/inteireza" (PORTAL; FRANCISCONE, 2007, p. 559).

\section{Das premissas à TESE}

Partindo dessas premissas sustenta-se a tese de que a Formação Continuada requer e pressupõe ações que possibilitem uma formação na perspectiva da Educação para a Inteireza do Ser. Isso implica compreender que, educar integralmente, como defende Yus (2002), pressupõe investir na

${ }^{3}$ Sujeito a quem dedicamos esse estudo.

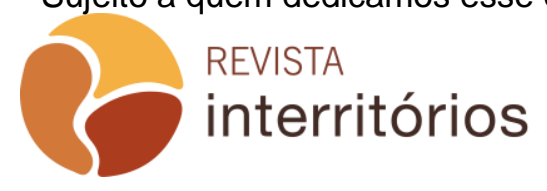


educação centrada no desenvolvimento interno e na exteriorização de suas capacidades num processo microssocial impelido a adotar atitudes de liberdade, respeito, responsabilidade.

Desse modo cabe ressaltar que a Educação para a Inteireza constitui-se numa proposta que implica e propõe desenvolver as dimensões constitutivas do SER - social, emocional, espiritual e racional (CATANANTE, 2000), ao instigar e inspirar o desenvolvimento do autoconhecimento, da autoformação. Nessa perspectiva a Formação Continuada "não se constrói por acumulação de cursos, de conhecimento ou de técnicas, mas [...] através de um trabalho de reflexibilidade crítica sobre práticas e de (re)construção permanente de uma identidade pessoal", num movimento que "vai e vem, avança e recua, construindo-se num processo de relações ao saber e ao conhecimento" (NÓVOA, 1995, p.03). Reverberando, segundo Palmer (2012), na "boa prática docente" que "não pode ser reduzida a técnicas", pois "ela vem da 'identidade e da integridade'4 do professor, [...] está impregnada de um forte senso de identidade pessoal" (p. 26).

Frente a esse contexto, oportuno destacar que a concepção da expressão "educação integral" parte da compreensão do significado etimológico da palavra "Educação", que tem origem em duas palavras latinas: "educare, por sua vez ligada a educere, verbo composto do prefixo ex (fora) + ducere (conduzir, levar), e que significa literalmente 'conduzir para fora', ou seja, preparar o indivíduo para o mundo" (DICIONÁRIO, 2015, s.p.); e do termo "integral", que tem origem no Latim Integrare e significa "tornar inteiro, fazer um só', de integer, 'inteiro, completo, correto', literalmente 'intocado', de in-, 'não', mais a raiz de tangere, 'tocar'” (ORIGEM, 2015, s.p.).

Wilber (2003) auxilia nesse entendimento ao esclarecer que compreende o termo "integral" como ação de reconciliar, juntar as partes, integrar, unir. Adverte que tal palavra não apresenta um sentido de uniformidade, completude, tão pouco relação com a tentativa de abolir as extraordinárias diferenças, mas sim um significado de unidade na diversidade, de partilha de características comuns. Advém da concepção e ampliação da consciência humana ao considerar e compreender o Ser humano em suas diferentes dimensões: corpo, mente, coração e espírito, tramadas na sensatez da inseparabilidade de suas interações e inter-relações (WILBER, 2003).

É nesse contexto que a Educação Integral é concebida e caracteriza-se "pela ideia de uma formação "mais completa possível' ${ }^{5}$ para o ser humano"

\footnotetext{
${ }^{4}$ Identidade e Integridade, segundo Palmer (2012), "são dimensões sutis do complexo, difícil e perpétuo processo de autoconhecimento. A identidade se encontra na intersecção das diversas forças que constroem a vida, e a integridade se encontra na relação com essas forças de um modo que elas me tragam plenitude de vida em vez de fragmentação e morte" (p. 29).

5 "Embora não haja consenso sobre o que se convenciona chamar de 'formação completa"” (BRASIL, 2009, p. 16).
} 
(BRASIL, 2009, p. 16). "Uma educação que promove o desenvolvimento [...] em suas múltiplas dimensões, considerando o corpo, a mente e a vida social, no sentido da construção da cidadania, do sujeito autônomo, crítico, participativo" (BRASIL, 2009, p. 19), e de relações.

A Educação Integral supõe/implica atenção a todas as potencialidades e dimensões humanas, suas inteligências, tomando em consideração 0 desenvolvimento, estilos cognitivos, capacidades intuitivas, artísticas, criativas, entre outras (YUS, 2002), apontando assim uma mudança de paradigma ${ }^{6}$. As raízes dessas mudanças encontram-se, segundo Yus (2002) "no pensamento de 'filósofos e educadores inovadores' que, ao longo do século $X X$, foram trazendo uma visão integral ou holística ${ }^{7}$ para a educação" (p. 34). Pois possibilitam perceber que, a cada nova época, novos paradigmas vão emergindo e delimitando padrões coletivos de formas de pensar. Essa mudança de visão, de acordo com Capra (2001), "requer uma expansão não apenas de nossas percepções e maneiras de pensar, mas também de nossos valores" (p. 27).

Desse modo, importante observar que o paradigma holístico é sustentado por concepções integradoras e humanizadoras, levando em conta sua visão de toda a forma de vida em nosso planeta ser transdisciplinar. ${ }^{8}$. Um olhar transdisciplinar, por sua vez, remete "a um todo significativo que emerge de um diálogo constante entre a parte e o todo, [...] busca encontrar os princípios convergentes" (MELLO, BARROS, SOMMERMAN, 2002, p. 10-11). Isso possibilita reconhecer a complexidade humana, a multidimensionalidade da realidade, seus níveis, a qual está formada em holarquias ${ }^{9}$ (GALLEGOS, 2015).

\footnotetext{
${ }^{6}$ Segundo Kuhn (1991, p.13) os "paradigmas são as realizações cientificas universalmente reconhecidas que, durante algum tempo, fornece problemas e soluções modelares para uma comunidade de praticantes de uma ciência". Com base na concepção de Thomas S. Kuhn, Yus (2002), esclarece que paradigma é um conjunto de regras que determina qual deve ser a conduta e a forma de resolver desafios dentro de alguns limites definidos para que se possa obter êxito. Segundo o autor, um paradigma nos condiciona a nossa "visão de mundo", a forma como nos aproximamos "dos temas" e nos envolvemos com o mundo exterior. Assim, a partir do momento em que um paradigma não oportuniza mais deliberar acerca dos desafios que emergem, descortina-se o surgimento de outro paradigma para que as mudanças ocorram. Consequentemente mudam as regras, e mudando-as, transformações ocorrem.

7 Uma visão de mundo holística, segundo Capra (2001), é uma visão "que concebe o mundo como um todo integrado, e não como uma coleção de partes dissociadas" (p.25). Segundo o referido autor, "na ciência do século XX, a perspectiva holística tornou-se conhecida como 'sistêmica', e a maneira de pensar que ela implica passou a ser conhecida como 'pensamento sistêmico"' (p. 33).

8 "Etimologicamente, trans é o que está ao mesmo tempo entre as disciplinas, através das diferentes disciplinas e além de todas as disciplinas, remetendo também à ideia de transcendência. O senso comum intui que todas essas inter-relações ocorrem no mundo e na vida". (MELLO, BARROS e SOMMERMAN, 2002, p. 10).

9 Para Gallegos (2015): "El concepto de holaquía permite integrar y al mismo tiempo superar los conceptos tradicionales de jerarquía (superior-inferior) y heterarquía (todo es igual), estos
}

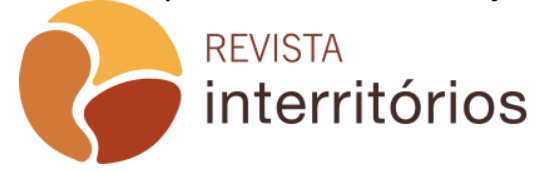

Interritórios | Revista de Educação Universidade Federal de Pernambuco, Caruaru, BRASIL | V.5 N.9 [2019] 
Para educar holisticamente ${ }^{10}$, os professores também devem formar-se holisticamente, intensificar essas capacidades ocultas, disfarçadas ou reprimidas por sua formação acadêmica e racionalista, procurar em todos os cantos de sua pessoa e buscar o equilíbrio que um educador precisa para transmitir confiança e apoio adequado para todos aqueles que procura educar. (YUS, 2002, p. 09).

\section{Caminho metodológico}

Diante do exposto, com o propósito de compreender como as Ações de Formação Continuada, ofertadas ao Professor de Creche pela Secretaria Municipal de Educação - SME de Florianópolis/SC, instigam uma formação na perspectiva de uma Educação para a Inteireza, investigou-se, por meio de uma pesquisa qualitativa de abordagem hermenêutica, como as Ações de Formação Continuada, ofertadas ao Professor de Creche pela Secretaria Municipal de Educação - SME de Florianópolis/SC, intencionam uma formação na perspectiva de uma Educação para a Inteireza.

A coleta de dados se deu por meio de pesquisa documental ${ }^{11}$ e entrevista semiestruturada ${ }^{12}$. A pesquisa documental teve início junto à base de dados do Sistema de Gerenciamento das Formações Permanentes - SIGEPE. Buscou-se ali identificar as Ações de Formação Continuada com maior número de Professores de Creche inscritos, porém, o sistema não oferecia tal informação haja vista não dispor de um campo no formulário ${ }^{13}$ de inscrição destinado a identificação do Grupo em que atua o Professor por ocasião da sua

enfoques, cuando se integram em holarquia permiten una mejor comprensión de la realidade. Holarquía es el desarrollo, por etapas, de redes más amplias de totalidade creciente, la realidade está dispuesta holárquicamente, contiene campos dentro de campos, la holarquía es el equilíbrio de la jeraquiía normal y la heterarquia normal" (E-book - posição 263 de 2708).

10 "O termo Educação Holística foi proposto pelo americano R. Miller (1997) para designar o trabalho de um conjunto heterogêneo de liberais, de humanistas e de românticos que têm em comum a convicção de que a personalidade global de cada criança deve ser considerada na educação. São consideradas todas as facetas da experiência humana, não só o intelecto racional e as responsabilidades de vocação e cidadania, mas também os aspectos físicos, emocionais, sociais, estéticos, criativos, intuitivos e espirituais inatos da natureza do ser humano". (YUS, 2002, p.16).

${ }^{11}$ A escolha pela pesquisa documental justifica-se por possibilitar também a "busca de informações em documentos que não receberam nenhum tratamento científico, como relatórios", projetos, "[...] entre outras matérias" (OLIVEIRA, 2007, p. 69). Importante esclarecer que, neste estudo, 'documento' é concebido como "qualquer suporte que contenha informação registrada, formando uma unidade, que possa servir para consulta, estudo ou prova" (APPOLINÁRIO, 2009, p. 67).

${ }^{12} \mathrm{~A}$ opção pela entrevista semiestruturada deu-se por reconhecer na possibilidade de combinar perguntas fechadas e abertas a oportunidade do entrevistado discorrer sobre o tema em questão (MINAYO, 2010).

${ }^{13}$ Detalhe alerta a rever os itens que compõem o referido formulário.

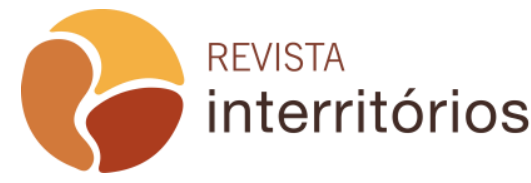


inscrição na formação, o que, infelizmente, impossibilitou realizar o mapeamento que identificasse o número de Professores de Creche que participaram das Ações de Formação Continuada, assim como, do grupo em que atuavam.

Diante do exposto a busca seguiu a partir dos descritores: profissionais da Educação Infantil, Professor de Creche, Professor de G1, G2 e G3. Foram identificadas 47 Ações de Formação Continuada ofertadas aos profissionais da Educação Infantil da RME, nos anos 2013, 2014 e 2015. Dessas, cinco foram destinadas a Professores, incluindo os Professores de Creche. E dessas cinco, duas foram ofertadas especificamente ao Professor de Creche, são elas: "Formação dos Profissionais da Rede Pública Municipal de Educação Infantil" (2013); "Espaço, Tempo e Currículo na Educação Infantil" (2014); "Programa de Formação Continuada para Educação Infantil” (2015); "Ações de Cuidado com Bebês: Diálogos entre Saúde e Educação" - "Alimentação para o Primeiro Ano de Vida" (2015); "I Simpósio Internacional sobre a Primeira Infância/SC" (2015).

De posse dessa informação, o passo seguinte foi pesquisar ${ }^{14}$ os formulários contendo as informações acerca de cada uma dessas Ações, assim como acessar ${ }^{15}$ os documentos a partir dos quais foram organizadas e implementadas as ações: Projeto de Formação Continuada (2013); Proposta de Formação Continuada (2014) e o Programa de Formação Continuada (2015).

As entrevistas foram realizadas junto a seis servidores efetivos da RME que exerciam, no referido período, a função de Diretor, Gerente ou Assessor junto à Diretoria de Educação Infantil - DEl(ii), à Gerência de Articulação Pedagógica e à Gerência de Formação Permanente - GEPE, por serem os responsáveis por pensar/planejar e implementar as ações de Formação Continuada ofertadas aos Professores de Creche.

A análise dos documentos e das entrevistas oportunizou concluir que, infelizmente, ainda existe uma lacuna na constituição da identidade profissional de muitos Professores de Creche, pois muitas vezes esse profissional não se reconhece como professor por não compreender o sentido/significado do binômio cuidar/educar ${ }^{16}$.

\footnotetext{
${ }^{14}$ Junto aos arquivos do Departamento de Eventos - DEVE (registro físico).

15 Junto a Diretoria de Educação Infantil - DEI.

${ }^{16}$ Educar exige cuidado; cuidar é educar, envolvendo acolher, ouvir, encorajar apoiar, no sentido de desenvolver o aprendizado de pensar e agir, cuidar de si, do outro, da escola, da natureza, da água, do Planeta. Educar é, enfim, enfrentar o desafio de lidar com gente, isto é, com criaturas tão imprevisíveis e diferentes quanto semelhantes, ao longo de uma existência inscrita na teia das relações humanas, neste mundo complexo. Educar com cuidado significa aprender a amar sem dependência, desenvolver a sensibilidade humana na relação de cada
} 
Assim a ausência da compreensão da concepção desse binômio aponta para uma lacuna que poderia e deveria ser contemplada a partir da perspectiva da Educação para a Inteireza, visto que os seus princípios, implicam diretamente o Ser e a identidade do Professor de Creche e essa, ser uma proposta transversal da/na Formação Continuada.

Nessa direção, ao analisar as concepções de Formação Continuada nutridas pela SME, foi possível constatar que essas foram sendo reformulas ${ }^{17} \mathrm{e}$ aprimoradas. A princípio, a Formação Continuada era concebida pela SME como espaço de diálogo interdisciplinar com o propósito de integrar teoria e prática educativa a fim de qualificar o trabalho pedagógico dos profissionais. $\mathrm{Na}$ sequência, passou a ser compreendida como um espaço de diálogo com uma proposta para: possibilitar reflexão entre teoria e prática, socialização e discussão; ressignificar conhecimentos e desenvolver habilidades referentes à inovação pedagógica. Essa proposta contemplava o acúmulo e a troca experiências e propunha ser uma formação orientadora, a fim de provocar a inquietação necessária que o trabalho educacional exige. Em uma nova concepção, adotada no ano seguinte, essa formação foi concebida também como um direito e dever desse profissional, pois compreendia-se que essa visava: a contemplação dos âmbitos da formação profissional individual; a ampliação do repertório vivencial e a formação profissional coletiva; a relação entre a formação desse profissional e a construção de práticas pedagógicas de qualidade; uma ação continuada, na qual a prática docente é tomada como ponto de partida e a mediação como meio da interação entre pares, professores formadores e a produção bibliográfica e documental da área.

\section{O que a pesquisa desvela}

Foi possível concluir que as concepções de Formação Continuada nutridas pela SME apontam atentar para a Educação Integral de um Ser Integral, assim como comunicam que essa não pode ser vista de forma separada da formação pessoal desse sujeito, pois visa a contemplar os âmbitos da formação profissional individual, da ampliação do repertório vivencial e da formação profissional coletiva.

Tomando a concepção dos entrevistados sobre Formação Continuada de uma formação que não termina, que envolve um processo contínuo e permanente, oportunizando aperfeiçoamento teórico e prático no próprio contexto de trabalho, que não deve estar restrita ao que o ambiente

um consigo, com o outro e com tudo o que existe, com zelo, ante uma situação que requer cautela em busca da formação humana plena (BRASIL, 2013, p.18).

${ }^{17}$ Ao longo dos três anos pesquisados. 
institucional oferece e possibilita - agregando às concepções expostas nos documentos chegamos ao entendimento de que para a SME, a Formação Continuada requer investir tanto na perspectiva da área profissional, como da pessoal, social, cultural; requer oportunizar reconstruir-se por meio de um movimento contínuo de ir e vir ao longo da vida profissional e viabilizar a ampliação de conhecimentos, constituindo-se como um alicerce, pois assim pode promover segurança, valorização, qualificação do profissional, experiência e aprendizado. Bem como compreender que a formação não se dá somente no processo formativo profissional individual, podendo se dar também no processo de mediação, na relação teoria-prática e na inter-relação entre a ação-reflexão-ação.

Embora a SME manifeste intencionar desenvolver junto aos bebês e às crianças bem pequenas uma Educação Integral por reconhecê-los como um Ser Integral, as ações de Formação Continuada ofertadas ao Professor de Creche, para instrumentalizá-lo a desenvolver esse trabalho, não foram pensadas, planejadas e implementadas por essa Secretaria com a intenção de propor a esse profissional contemplar as dimensões constitutivas do Ser (social, emocional, espiritual e racional), conforme informaram os entrevistados.

Destarte, o que se observa é que as ações de Formação Continuada ofertadas no período da pesquisa não intencionavam metodologicamente disponibilizar ao Professor de Creche uma Educação na perspectiva da Inteireza. Entretanto, considera-se que, mesmo as ações de Formação não tendo sido pensadas e planejadas com esse propósito, de alguma forma, as dimensões constitutivas do Ser permearam sutilmente o desenvolvimento das ações de Formação propostas na ocasião.

De tal modo, como as concepções, as Ações de Formação Continuada da SME fora $\mathrm{m}$ sendo modificadas e começaram a ser direcionadas/oferecidas especificamente ao Professor de Creche. Porém, cabe ressaltar que os entrevistados, expressaram que eles não identificam claramente o que compõem a orientação voltada para Inteireza, no que tange às propostas de ações, apesar de reconhecerem seus princípios quando revisitaram as ações realizadas nesses anos. Reconhecem o pouco conhecimento sobre o que caracteriza a Educação na perspectiva da Inteireza e, portanto, consideram esse um dos entraves para o planejamento das ações nessa perspectiva.

Chamou a atenção, também, a baixa compreensão da concepção das dimensões constitutivas do Ser, ou seja, as dimensões que compõem a Educação na perspectiva da Inteireza (social, emocional, espiritual e racional), em especial a dimensão espiritual.

Foi possível constatar que há uma confusão e que essa se dá por relacionarem a dimensão espiritual com religião e não com o desenvolvimento do que confere sentido, significado a razão de existir, o propósito de vida da 
pessoa, as lições que se veio aprender e ensinar, "o que é reflexo das experiências que se repetem continuamente" (CATANANTE, 2000). Ou seja, apesar da SME reconhecer a importância e a necessidade de desenvolver uma Educação Integral para um Ser Integral, ainda ocorre um equívoco na compreensão das dimensões constitutivas do Ser. Cabe ressaltar que este estudo não objetivava um processo de avaliação sobre as ações de Formação Continuada ofertadas pela SME e, portanto, não pretende apontar falhas.

A intenção de compreender como essa Formação foi instigada, aponta que a SME está a caminho de uma Formação Continuada na perspectiva de uma Educação para a Inteireza, levando em consideração que este é justamente o momento para se exigir um olhar mais atento para a Formação Continuada.

Como forma de colaborar com a SME, cabe ressaltar que se notou, a partir das entrevistas, a necessidade, assim como se identificou o interesse de investimentir em estudos que possibilitem aos gestores entenderem o que caracteriza cada uma das dimensões do Ser e o como se constitui a Formação Continuada na perspectiva de uma Educação para a Inteireza. Isso requer estimular o investimento em autoconhecimento, em autoformação e no desenvolvimento da transdisciplinaridade, que exige uma atitude integral de desenvolvimento interior, comprometida e responsável com a percepção das múltiplas realidades. Da mesma forma, sugere-se que estes estudos sejam disponibilizados ao Professor de Creche da RME, pois o professor não pode ensinar o que não sabe e esse saber não pode ser um saber do qual apenas se fala, mas pelo contrário, deve ser o saber que se vive concretamente, como Freire (1997) apontou.

Por fim, cabe reiterar que a Educação para a Inteireza constitui-se numa proposta que implica e propõe desenvolver as dimensões constitutivas do Ser (social, emocional, espiritual e racional) ao instigar e inspirar o desenvolvimento do autoconhecimento, da autoformação num movimento transdisciplinar que busca compreender a complementariedade, a sinergia que envolve e circula por entre essas dimensões assim como pressupõe o fortalecimento da identidade do Professor de Creche, que, ao cuidar/educar do/o bebê e da/a criança bem pequena, participa ativamente na formação desse Ser.

Na verdade é chegada a hora de semear a fé e fincar raízes no terreno fértil da esperança. Esperança em uma educação renovadora e inovadora, libertadora e criativa, capaz de sinalizar a abertura de novos caminhos, emergência de novas possibilidades de construção e reconstrução do mundo e da vida. É tempo de reencantar a educação! E, como humanidade, é tempo de transcendência, tempo de emergência da civilização da religação. (MORAES, 2004, p. 327). 


\section{REFERÊNCIAS}

APPOLINÁRIO, F. Dicionário de metodologia científica: um guia para a produção do conhecimento científico. São Paulo: Atlas, 2009.

BRASIL. Série Educação Integral. Texto Referência para o Debate Nacional. 2009. Disponível em: http://portal.mec.gov.br/dmdocuments/cadfinal_educ_integral.pdf. Acesso em: 1ำ nov. 2015.

BRASIL. Diretrizes Curriculares Nacionais para Educação Básica. Disponível em: http://portal.mec.gov.br/index.php?option=com_docman\&view=download\&alias=13677 -diretrizes-educacao-basica-2013-pdf\&Itemid=30192. Acesso em: 1ํo nov. 2015.

CAPRA, F. Teia da Vida. 6. ed. São Paulo: Cultrix, 2001.

CATANANTE, B. A gestão do ser integral: como integrar alma, coração e razão no trabalho e na vida. São Paulo: Infinito, 2000.

CELLARD, A. A análise documental. In: POUPART, J. et al. A pesquisa qualitativa: enfoques epistemológicos e metodológicos. Petrópolis, Vozes, 2008.

CHARLOT, B. Da Relação com o Saber. Porto Alegre: ARTMED, 2000.

DICIONÁRIO ETIMOLÓGICO, 2015. Disponível em:

http://www.dicionarioetimologico.com.br/educar/. Acesso em: 09 nov. 2015.

FLORIANÓPOLIS. Diretrizes Curriculares para a Educação Infantil. Disponível em: http://www.pmf.sc.gov.br/arquivos/arquivos/pdf/25_05_2015_13.21.19.a8cfbc1ba4550 2447185ee928a98ce06.pdf. Acesso em: 24 ago. 2015a.

FREIRE, P. Pedagogia da autonomia. São Paulo: Editora Paz e Terra, 1997.

GALLEGOS, R. N. Uma Visión Integral de la Educacion - El corazón de lá educacion holista. Primeira Edición - ISBN e-Book: 978-607-00-3799-3. Guadalajara, Jal. México: Fundación Internacional para la Educación Holista. 2015.

KUHN, T. S. A estrutura das revoluções científicas. São Paulo: Perspectiva, 1991.

MELLO, BARROS, SOMMERMAN. Educação e transdisciplinaridade. São Paulo: TRIOM, 2002.

MINAYO, M. (org.); GOMES, S. Pesquisa Social: Teoria, método e criatividade. Rio de Janeiro: Vozes, 2010, p. 243-256.

MORAES, M. C. Pensamento ecossistêmico, educação, aprendizagem e cidadania no século XXI. Petrópolis: Vozes, 2004.

MORAES, R e GALLIAZZI, M. C. Análise textual discursiva. ljui: Ed. UNIJUI, 2013.

NÓVOA, A. Formação de professores e profissão docente. In: NÓVOA, A. Os professores e a sua formação. 2 ed. Lisboa: Nova Enciclopédia, 1995.

NÓVOA, A. Professores: imagens do futuro presente. Lisboa: Educa, 2009. 
OLIVEIRA, M. M. Como fazer pesquisa qualitativa. Petrópolis, Vozes, 2007.

ORIGEM DAS PALAVRAS, 2015. Disponível em:

http://origemdapalavra.com.br/site/palavras/integral/. Acesso em: 09 nov. 2015.

PALMER, P. J. A coragem de ensinar: a vocação, as dificuldades e o potencial transformador de um professor. São Paulo: Editora da Boa Prosa, 2012.

PORTA, L. L; FRANCISCONE, F. Contribuições da Educação Continuada na construção da inteireza dos docentes da educação superior. Educação. Porto Alegre/RS, ano XXX, n³(63), p. 557-569, 2007. Disponível em:

http://revistaseletronicas.pucrs.br/ojs/index.php/faced/article/viewFile/2750/2097. Acesso em: 28 set. 2012.

WILBER, K. Uma teoria de tudo: uma visão integral para os negócios, a política, a ciência e a espiritualidade. São Paulo: Cultrix, 2003.

YUS, R. Educação integral, uma educação holística para o século XXI. Porto Alegre: Artes Médicas, 2002. 